Supporting Information for

\title{
Precision, Tunable Deuterated Polyethylene via Polyhomologation
}

\author{
authored by \\ Wesley S. Farrell ${ }^{\dagger,}$, Sara V. Orski ${ }^{\dagger}$, Anthony P. Kotula ${ }^{\dagger}$, Daniel W. Baugh III', Chad R. Snyder ${ }^{\dagger}$, \& \\ Kathryn L. Beers ${ }^{\dagger, *}$
}

†Materials Science \& Engineering Division, National Institute of Standards \& Technology ${ }^{\S}, 100$ Bureau Drive, Gaithersburg, Maryland 20899, United States.

¥The Dow Chemical Company, 230 Abner Jackson Parkway, Lake Jackson, Texas 77566, United States.

${ }^{\S}$ Official contribution of the National Institute of Standards \& Technology; not subject to copyright in the United States.

॥Present Address: Chemistry Department, United States Naval Academy, 572M Holloway Rd, Annapolis, Maryland 21402, United States.

E-Mail: kathryn.beers@nist.gov 


\section{TABLE OF CONTENTS}

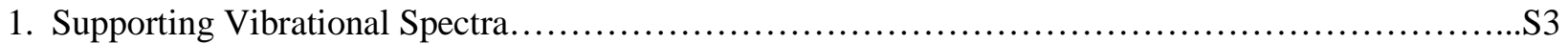

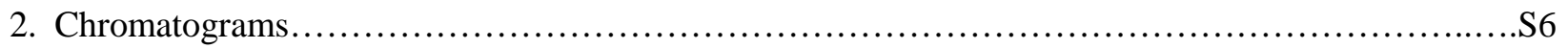

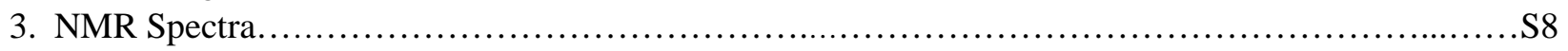

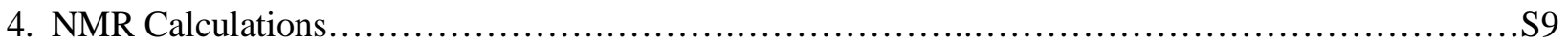

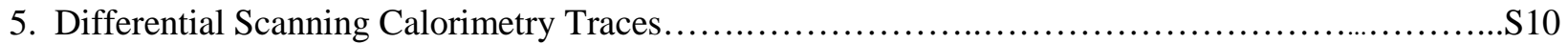




\section{SUPPORTING VIBRATIONAL SPECTRA}

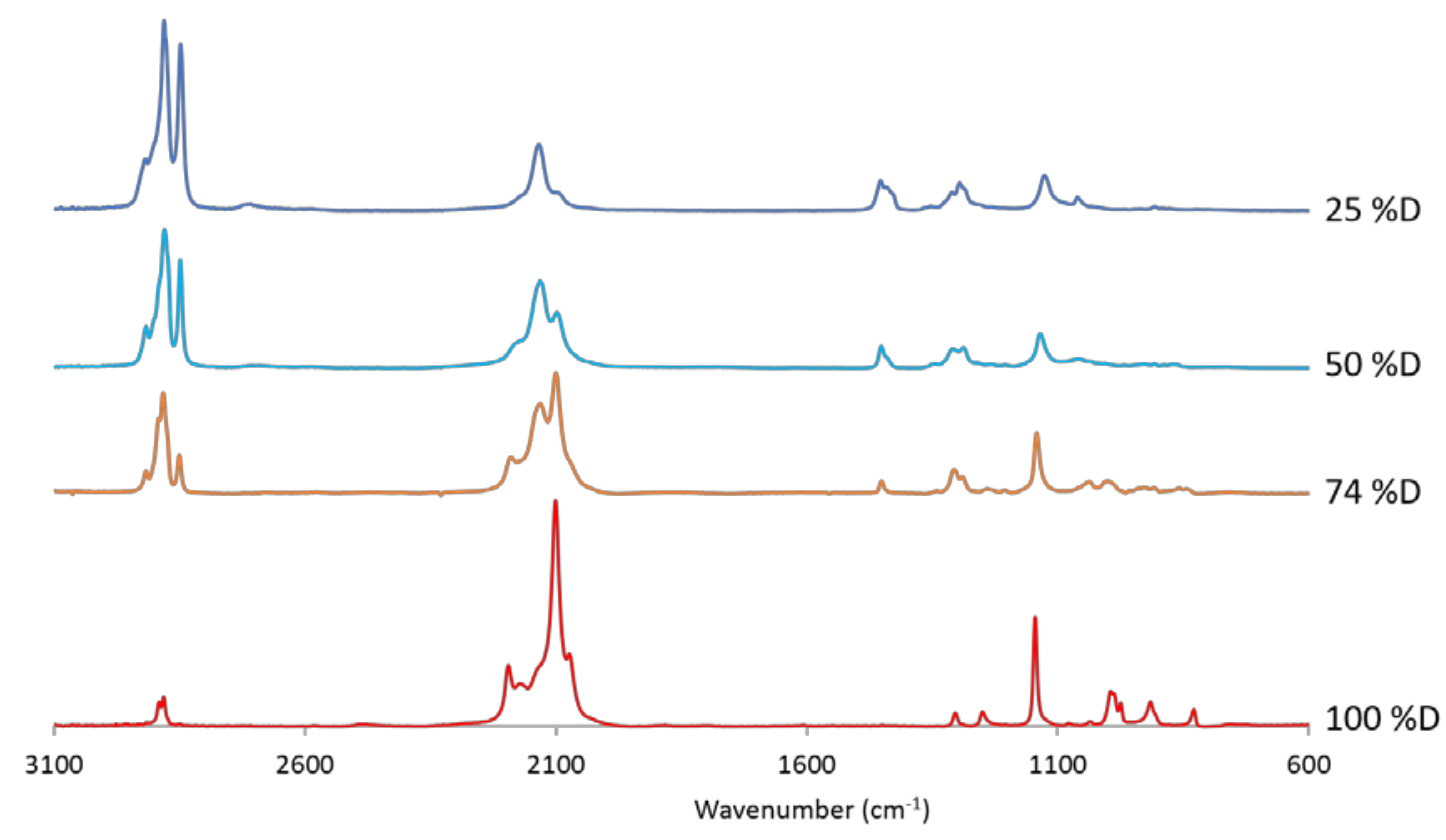

Figure S1. Raman spectra of partially deuterated polyethylenes. Note: Samples were melted and recrystallized prior to measurement.

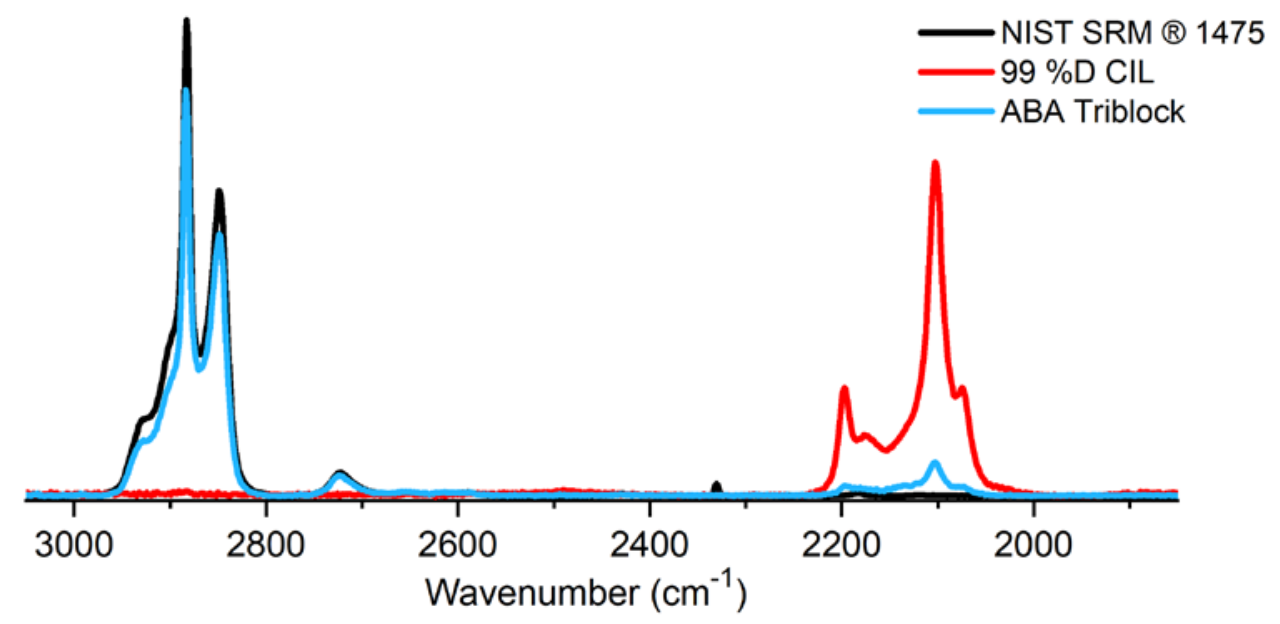

Figure S2. Partial Raman spectra of ABA triblock copolymer (melted and recrystallized prior to measurement), along with NIST SRM ${ }^{\circledR} 1475$ and 99\%D PE, obtained from Cambridge Isotope Laboratories, for comparison. Reference materials were not melted and recrystallized prior to measurement. 


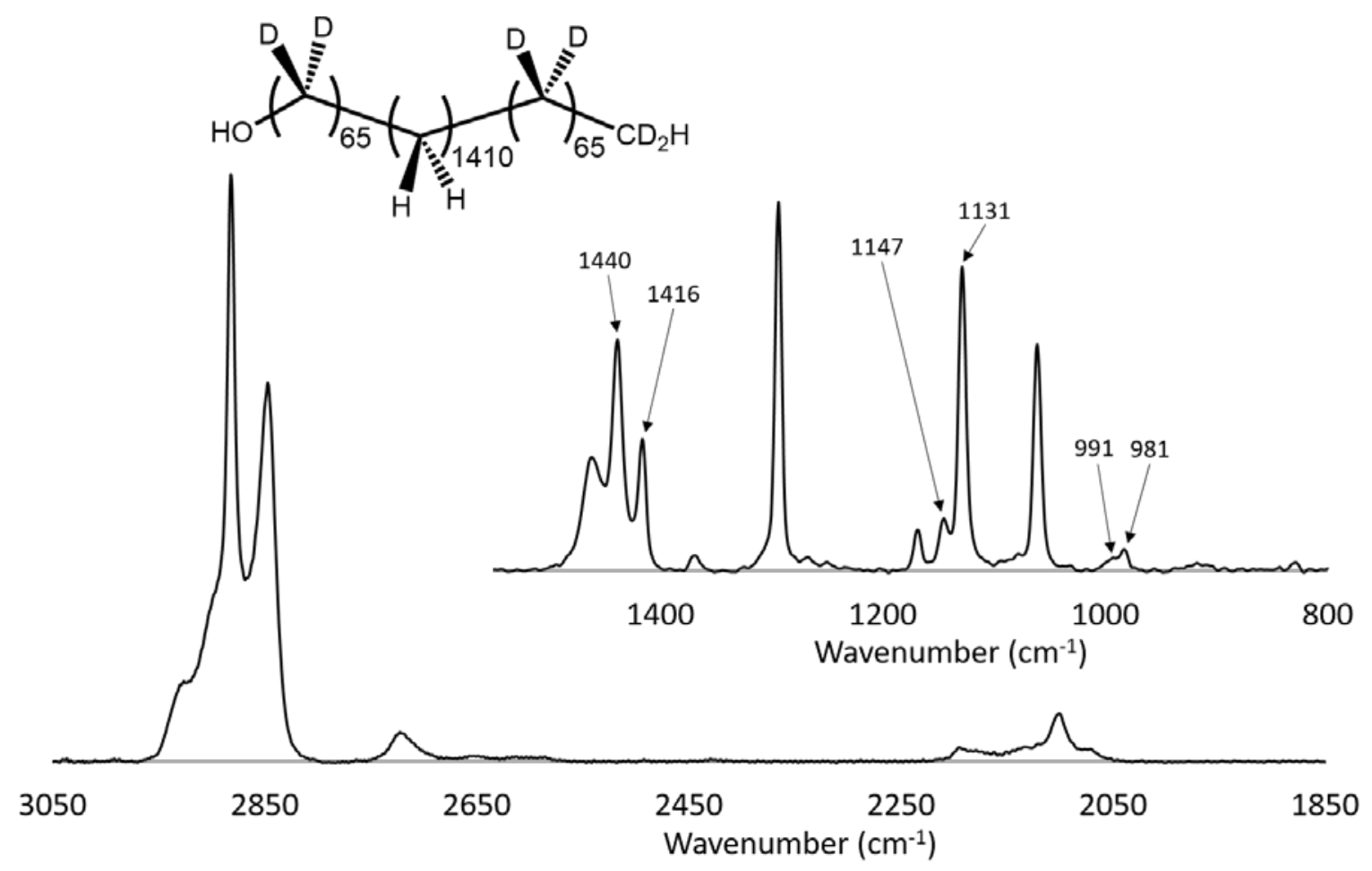

Figure S3. Partial Raman spectra of ABA triblock copolymer with selected peaks labeled. Note: Sample was melted and recrystallized prior to measurement.

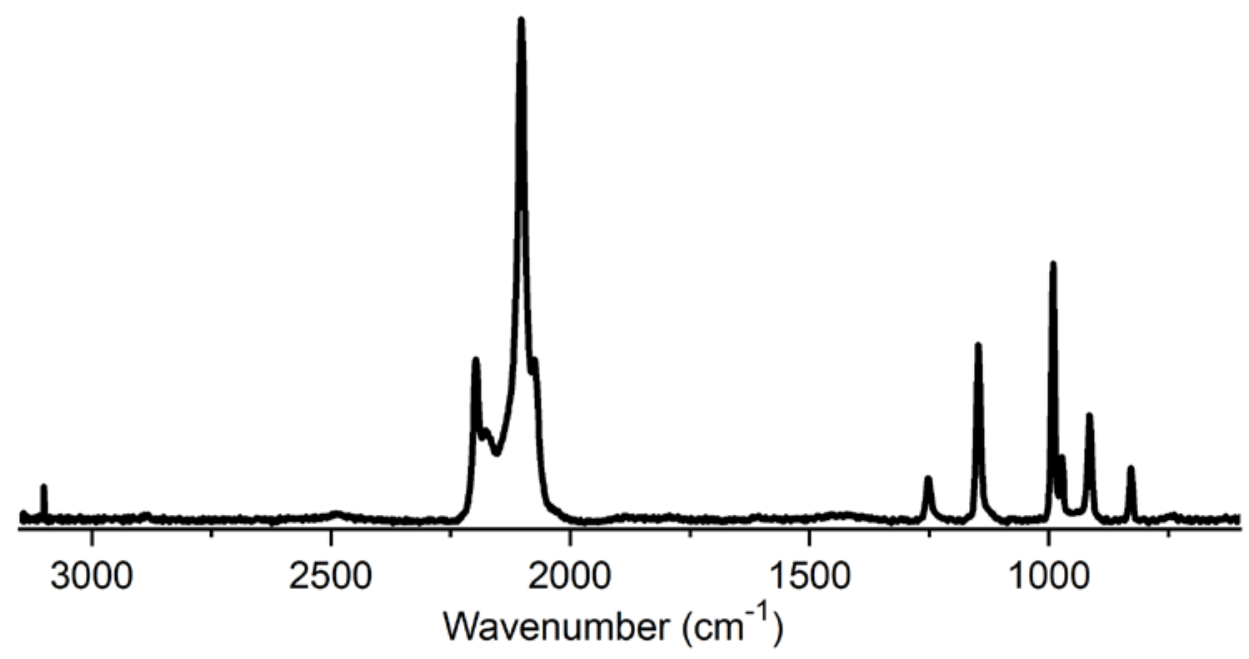

Figure S4. Raman spectrum 99 \%D polyethylene purchased from Cambridge Isotope Laboratories. (Note: This material was measured as received, without melting and recrystallization). 


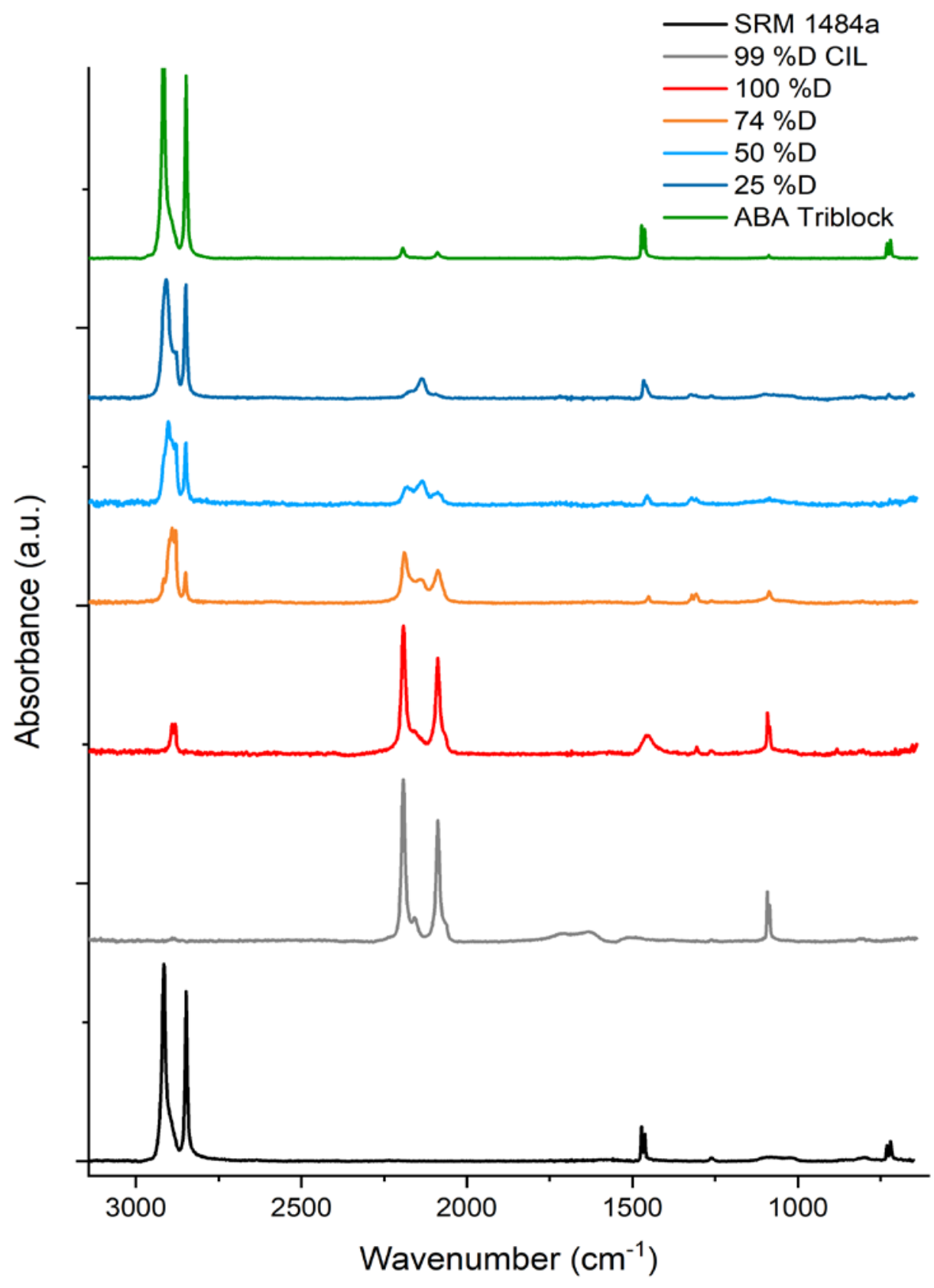

Figure S5. IR spectra of partially deuterated polyethylenes, and NIST SRM ${ }^{\circledR} 1484 a$ and 99\%D PE obtained from Cambridge Isotope Laboratories for reference. Note, reference materials were used as received without melting and recrystallization, while polyethylenes made via polyhomologation were melted and recrystallized prior to measurement. Absorbance intensity of all data is normalized based on the total area of the C-H and C-D stretching regions from $2000-3000 \mathrm{~cm}^{-1}$ for comparison. 


\section{CHROMATOGRAMS}

a

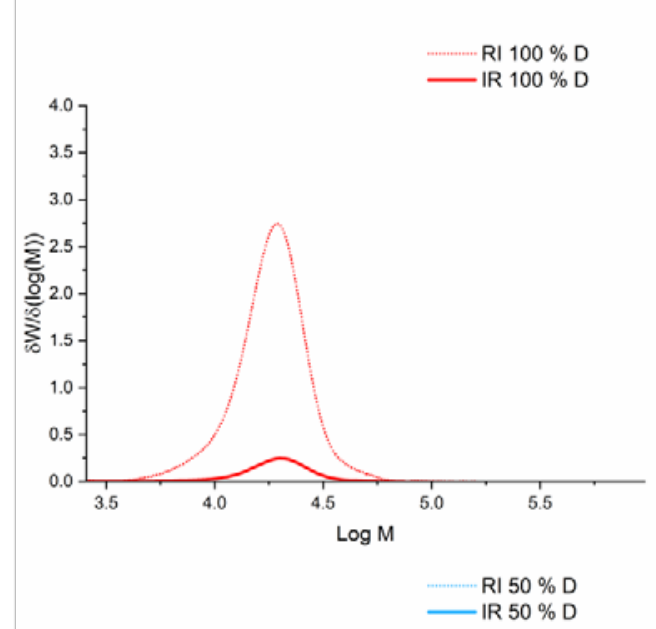

C

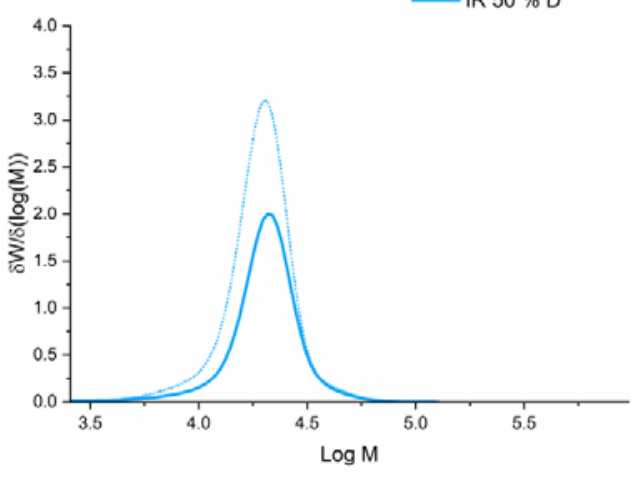

b

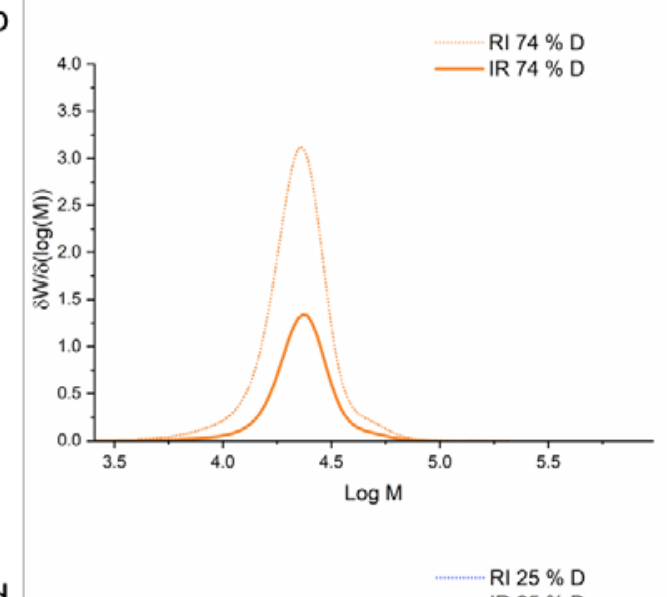

d

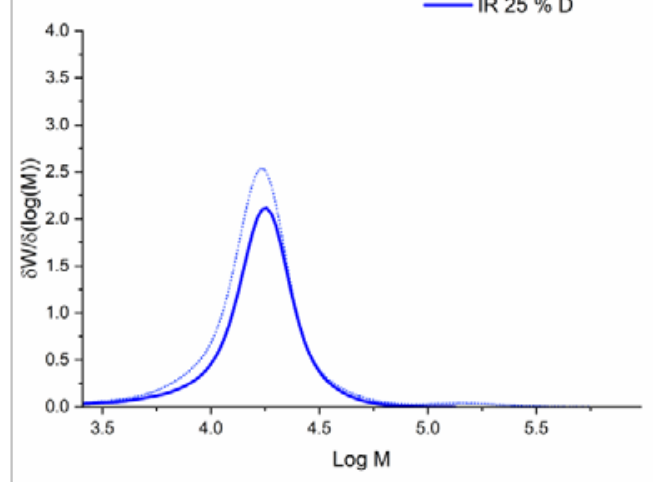

Figure S6. Molar mass distributions (MMDs) for partially deuterated polyethylenes made via polyhomologation. MMDs were separately measured using IR (solid) and RI (dashed) concentration detectors. The MMDs from the IR data are normalized to the mass recovery calculated by SEC-IR 
a

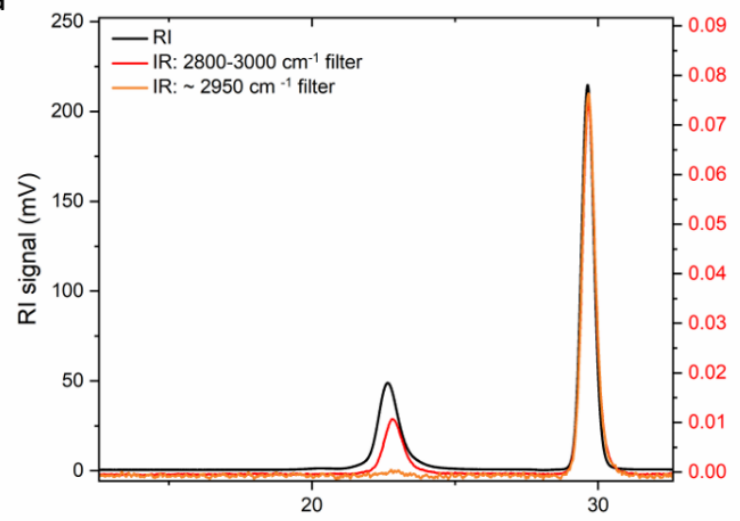

C

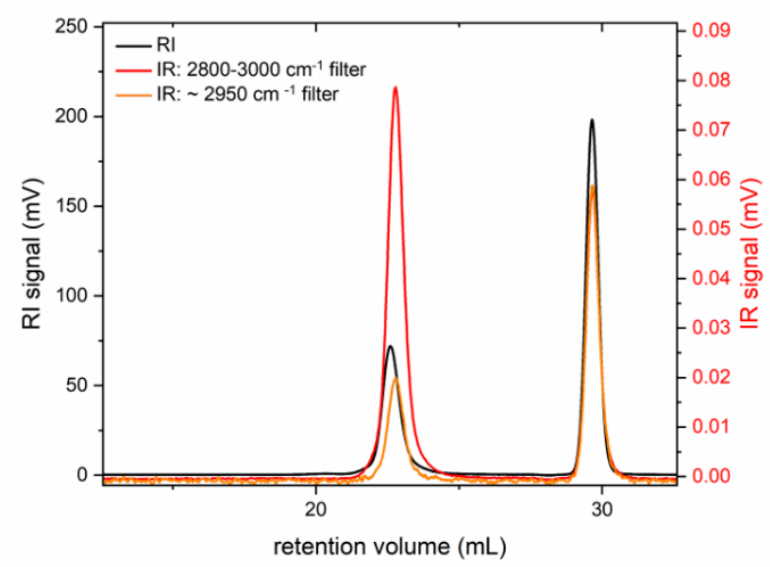

b

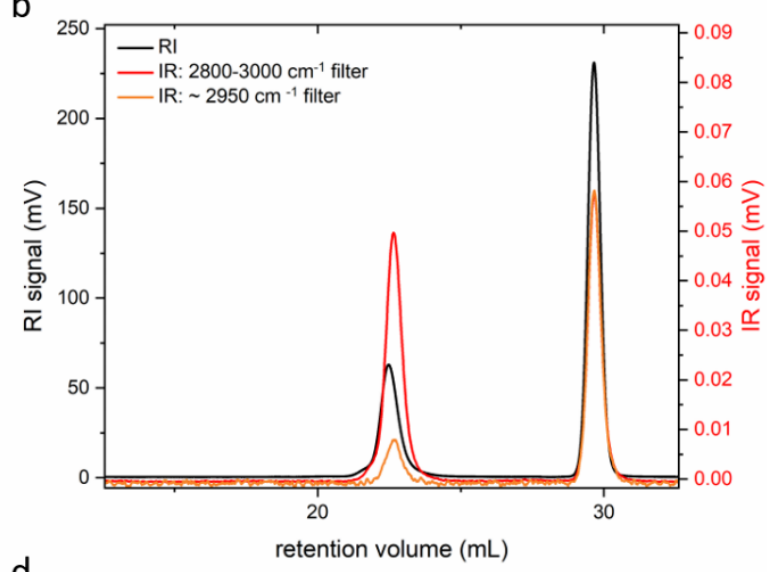

d

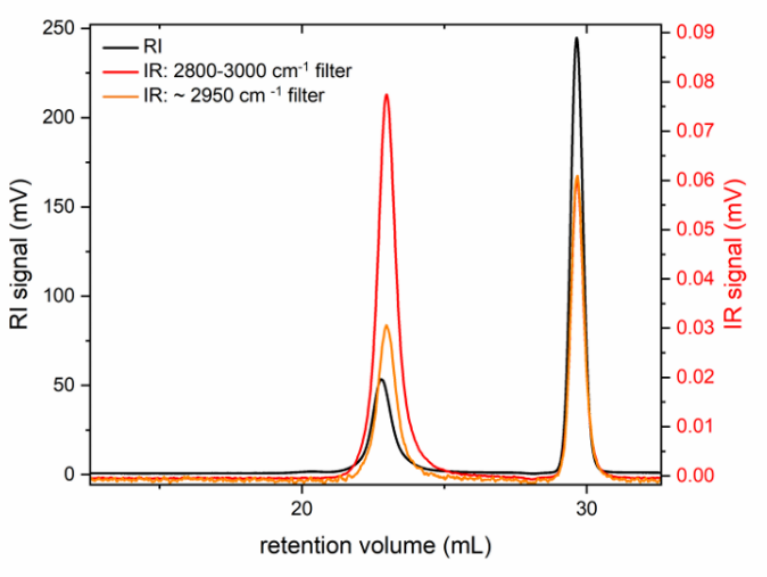

Figure S7. Concentration detector traces for partially deuterated polyethylenes made via polyhomologation: a.) $100 \% \mathrm{D}$ b.) $74 \% \mathrm{D}$ c.) $50 \% \mathrm{D}$ d.) $25 \% \mathrm{D}$. The peak at $\sim 29.5 \mathrm{~mL}$ in all chromatograms is dodecane, used as a flow rate marker. The RI and IR data are not normalized to each other. 
a

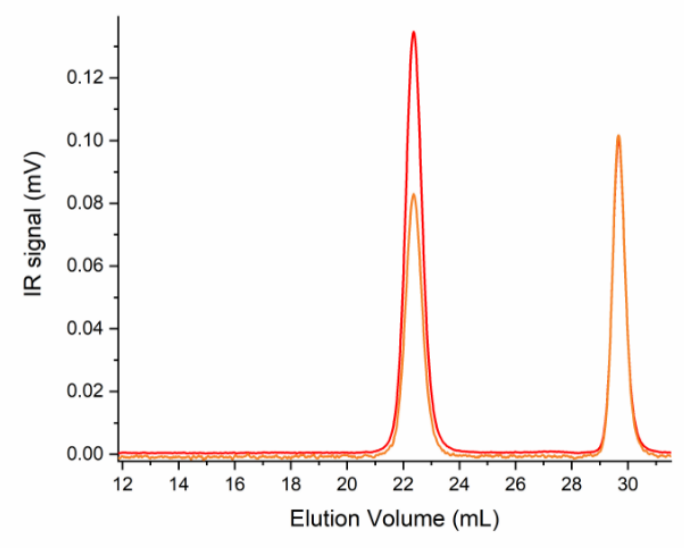

b

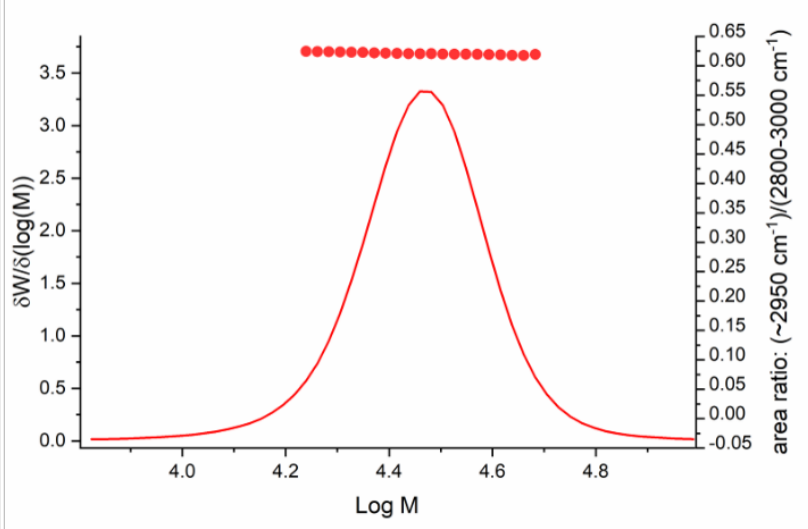

Figure S8. a) Molar mass distribution for partially deuterated polyethylene ABA block copolymer made via polyhomologation as measured by SEC-IR. The red curve is the entire $\mathrm{C}-\mathrm{H}$ stretching region, and the orange curve is the C-H stretching measured at $2950 \mathrm{~cm}^{-1}$. b) Area ratio of signal measured at $2950 \mathrm{~cm}^{-1}$ signal and $2800-3000 \mathrm{~cm}^{-1}$ range as function of molar mass.

\section{NMR SPECTRA}

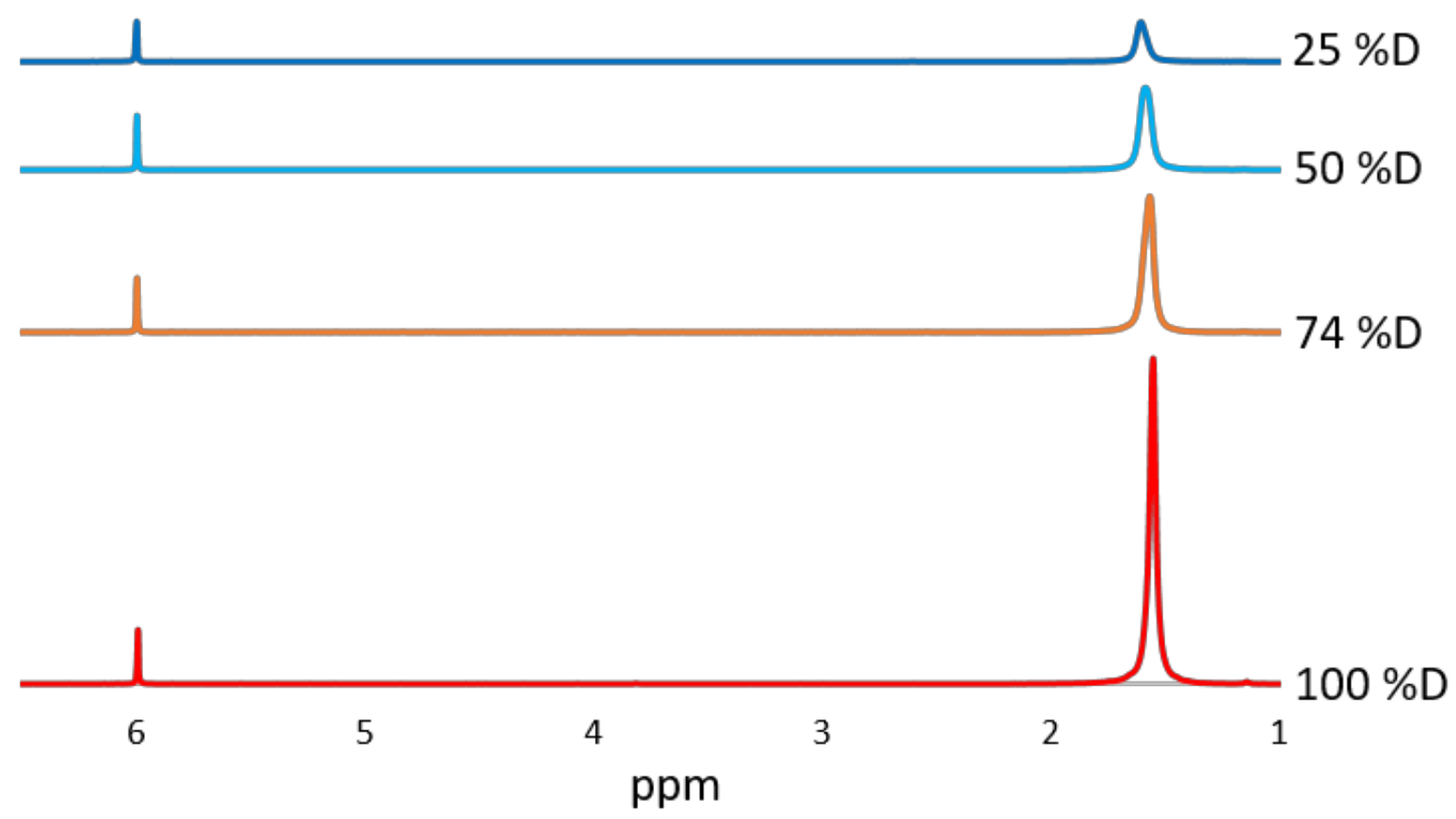

Figure S9. Partial ${ }^{2} \mathrm{H}$ NMR spectra, normalized by tetrachloroethane- $d_{2}$ signal at $6.0 \mathrm{ppm}$, which is used as an internal standard. 


\section{NMR CALCULATIONS}

Example calculation of mol \%D for sample III, $50 \mathrm{~mol} \% \mathrm{D}$

In the most general sense, this method requires weighting the moles ${ }^{1} \mathrm{H}$ and ${ }^{2} \mathrm{H}$ according to the weight fractions of the ${ }^{1} \mathrm{H}$ containing species and the ${ }^{2} \mathrm{H}$ containing species present in the sample. In the current case, where the material is $\mathrm{PE}$, and the ${ }^{1} \mathrm{H}$ and ${ }^{2} \mathrm{H}$ containing species can be assumed to be $\mathrm{CH}_{2}$ and $\mathrm{CD}_{2}$ units only, the math is simple because the mass $\% \mathrm{CD}_{2}$ can be calculated directly from the polymer mass and the NMR measured moles ${ }^{2} \mathrm{H}$. This is illustrated in the table and calculation below, where the moles ${ }^{1} \mathrm{H}$ and ${ }^{2} \mathrm{H}$ are determined by:

- Determining the moles ${ }^{2} \mathrm{H}$ by NMR

- Determining the moles $\mathrm{CD}_{2}$ present in the sample from this information

- Determining the mass $\mathrm{CD}_{2}$ present in the sample from this information

- Determining the mass $\mathrm{CH}_{2}$ present in the sample by subtracting mass $\mathrm{CD}_{2}$ determined from the total mass of polymer sample

- Determining the moles $\mathrm{CH}_{2}$ present from this information

- Determining the moles ${ }^{1} \mathrm{H}$ present from this information

Table S1. Example calculations of mol\% D in sample III.

\begin{tabular}{|c|c|}
\hline Sample ID & III \\
\hline Solvent stock weight (g) & 0.6960 \\
\hline Sample Weight (g) & 0.0088 \\
\hline Internal std. molar mass (g/mol) $\left(\right.$ TCE- $\left.d_{2}\right)$ & 169.8622 \\
\hline TCE- $d_{2}$ atom $\% \mathrm{D}$ & 99.8 \\
\hline Mass int. std. (TCE- $d_{2}$ ) in sample (g) & 0.004106 \\
\hline Int. std. (TCE- $\left.d_{2}\right)$ integral & 1000 \\
\hline Total polymer mass in sample (g) & 0.0088 \\
\hline Total polymer ${ }^{2} \mathrm{H}$ integral & 12199.89 \\
\hline Total moles of ${ }^{2} \mathrm{H}$ from internal std. in sample & 4.8247E-05 \\
\hline Integral units / mole ${ }^{2} \mathrm{H}$ & $2.0727 \mathrm{E}+07$ \\
\hline Moles ${ }^{2} \mathrm{H}$ in sample measured by NMR & 0.0005886 \\
\hline Mass of polymer from $\mathrm{CD}_{2}$ units (g) & 0.0047204 \\
\hline Mass $\% \mathrm{CD}_{2}$ & 53.64 \\
\hline Mass of polymer from $\mathrm{CH}_{2}(\mathrm{~g})$ & 0.0040796 \\
\hline Moles ${ }^{1} \mathrm{H}$ from polymer & 0.0005817 \\
\hline Total moles ${ }^{1} \mathrm{H}+{ }^{2} \mathrm{H}$ in sample & 0.0011703 \\
\hline Mol\% ${ }^{2} \mathbf{H}\left[\mathrm{mol}^{2} \mathrm{H} /\left(\mathrm{mol}^{2} \mathrm{H}+\mathrm{mol}^{1} \mathrm{H}\right)\right] \times 100 \%$ & $50.3 \%$ \\
\hline
\end{tabular}




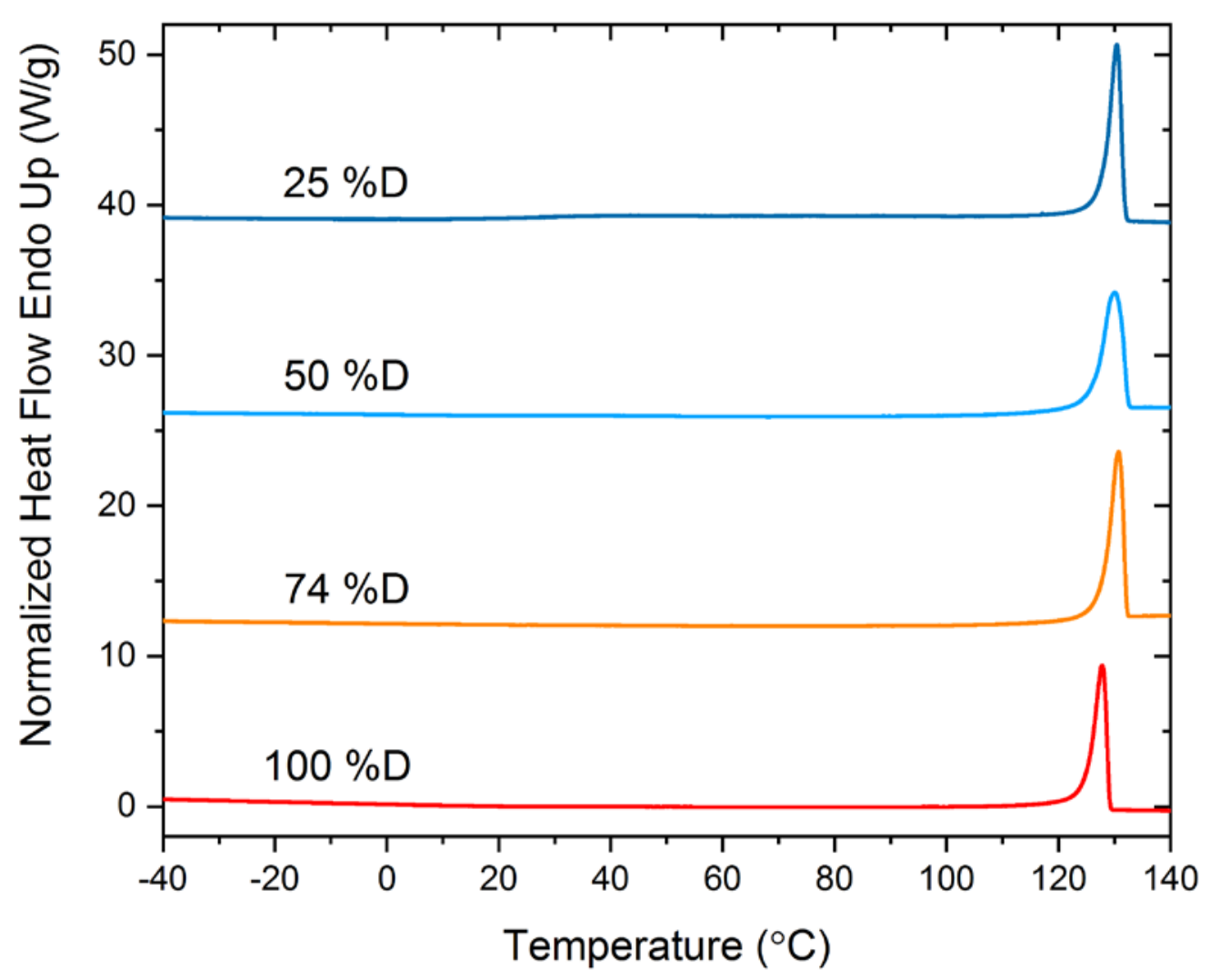

Figure S10. DSC traces of partially deuterated polyethylenes. Traces have been offset vertically for clarity. (Endotherm direction is up.) 